\title{
Translucency of Clear Acrylic Resin influenced by Oil Paints
}

\author{
Firas Abd Kati
}

(Lecturer)

Department of Optical Techniques, College of Health \& Medical Technology, Baghdad, Middle Technical University, Baghdad, Iraq

\begin{abstract}
Introduction: Clear acrylic resins are widely used in many applications in the field of dentistry such as removable complete and partial dentures. such materials are also used in the fabrication of scleral part of ocular prostheses when mixed with white oil paints. Therefore, the purpose of the present study was to evaluate the addition of oil paints on translucency of clear acrylic material.

Materials and methods: The study included three main groups. Each group consists of 10 specimens. The concentration of white oil paints has increased from $1 \mathrm{ml}$ to $2 \mathrm{ml}$, respectively. The translucency test was applied on all specimens.

Results: The results showed that there was a significant decrease in translucency of acrylic following addition of white oil paints. Conclusion: the use of white paints has decreased the translucency of acrylic material. The adding of white oil paint at $1 \mathrm{ml}$ to clear acrylic resin is necessary in the manufacture of the scleral part of ocular prostheses to match the colour of natural eye.
\end{abstract}

\section{KEYWORDS}

translucency, oil paints, ocular prosthesis

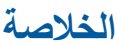

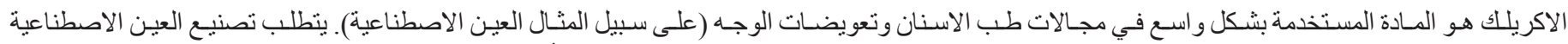

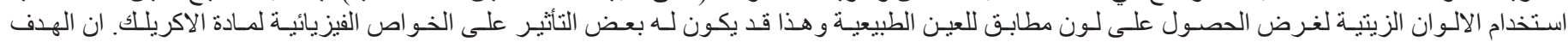

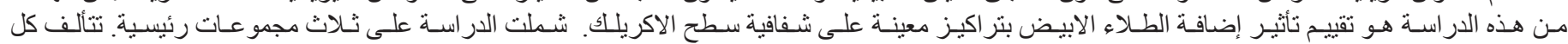

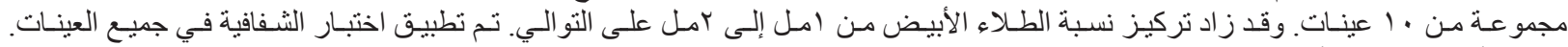

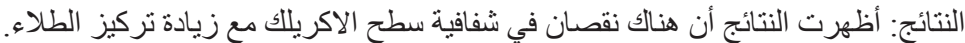
الاستنتاج: اضافة صبغة التيتانيوم الو ايت اثر بصورة كبيرة على شفافية الاكريلك.

\section{INTRODUCTION}

Clear acrylic resins are considered as the most commonly substances used in dentistry in the fabrication of removable prostheses, for example, complete and partials dentures ${ }^{(1-2)}$. These materials can be also used over scleral part of artificial eyes when mixed with white oil paints to obtain a colour similar to the natural eye ${ }^{(3-4)}$. For patients with ocular deformity, artificial eyes provide the professional and social acceptance, maintains the size of the socket and increases the patient's confidence in the public ${ }^{(5,6)}$. Generally, white coloured acrylic materials are widely used to make the scleral part of the artificial eye $^{(7)}$. However, these materials are not sufficiently available in domestic markets. Clear acrylic resins are, therefore, mixed with oil paints in order to match colour of the natural eye. Materials which are used in construction of ocular prostheses must have appropriate properties such as excellent aesthetics, durability, biocompatibility and non-irritating to the eye socket and bilateral stability ${ }^{(8-9)}$. This study was conducted, hence, to assess the translucency of acrylic resin following the addition of white oil paint.

\section{MATERIALS AND METHODS}

\section{Materials and sample preparation}

The materials utilized In current study, were clear heat polymerizing acrylic (Zhermack, Italy ), and titanium dioxide pigment (Grumbacher, USA) as well as Dental stone (Zhermack, Italy) as a mould material. There were 3 main groups. Groups without addition of titanium dioxide were considered as control. White acrylic samples were made of acrylic resin with the addition of oil paint with either $1 \mathrm{ml}$ or $2 \mathrm{ml}$ oil paint.

\section{Preparation of acrylic specimens}

Wax patterns with dimensions of $2 \mathrm{~mm}$ and 30 $\mathrm{mm}$ diameter were manufactured to make acrylic specimens for translucency testing. Acrylic samples were constructed using traditional flasking techniques (10). Wax patterns were centered at the bottom of the metal flask, which was separated with a Vaseline in order to take the stone mould out after deflasking. According to the manufacturer's instructions, dental stone was mixed with water $(100 \mathrm{~g} / 25 \mathrm{~m} 1)$, placed at the bottom, wax patterns were positioned with half of them exposed to be easily removed from the mould (Figure 1). 


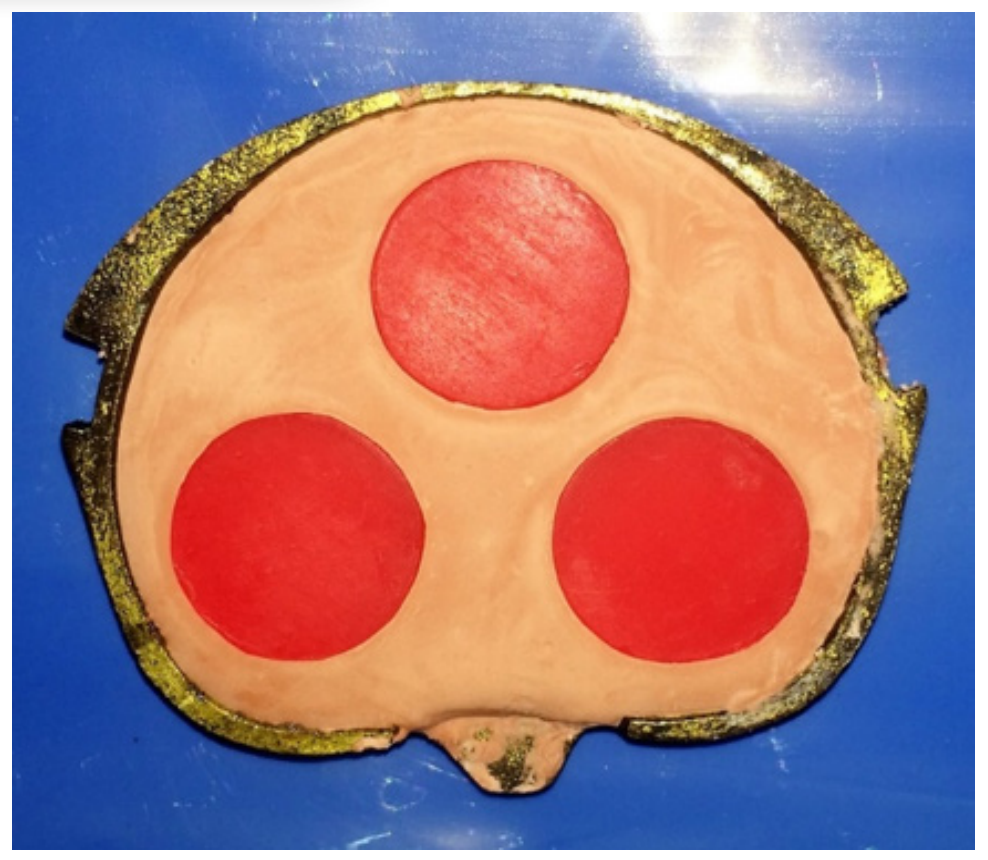

Figure 1. Wax pattern for translucency test

The upper part was coated with a Vaseline machine for 5 minutes to remove all the wax. The following complete set of stone surface, and then upper and lower parts were then separated; and positioned over the lower part and filled with dental detergents were used to remove the waxy residue stone. After one hour, the flask was put into boil out completely from the stone mould(Figure 2).

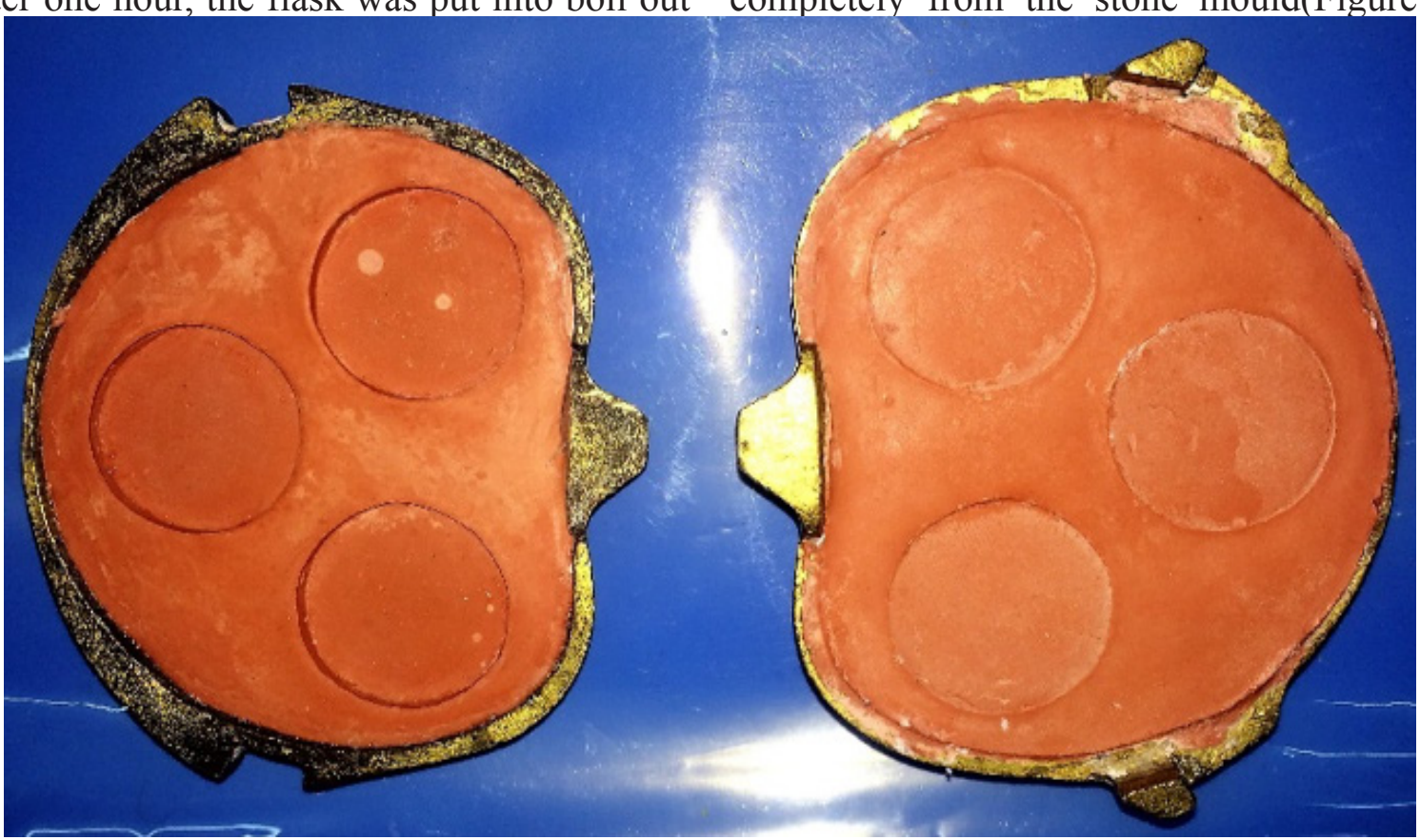

Figure 2 . mould preparation

The control specimens were made by mixing $22 \mathrm{~g}$ monomer for white 1 group, and adding $2 \mathrm{ml}$ white oil of acrylic powder with $10 \mathrm{ml}$ of monomer. The acrylic was packed into mould when it reached into dough stage. According to the manufacturer instructions, the acrylic was cured in water path machine. Once curing, the flask was left to cool; and samples were then removed from the flask, finished and polished. The white acrylic specimens were made via the above process with adding $1 \mathrm{ml}$ white oil paint to $9 \mathrm{ml}$ liquid paint to $8 \mathrm{ml}$ of monomer for White 2 group.

\section{Translucency test}

The colour of each specimen was measured using a spectrophotometer (Metertech, Taiwan). The specimen was tested three times (left, middle, right); and average readings were calculated for each specimen (Figure 3). 


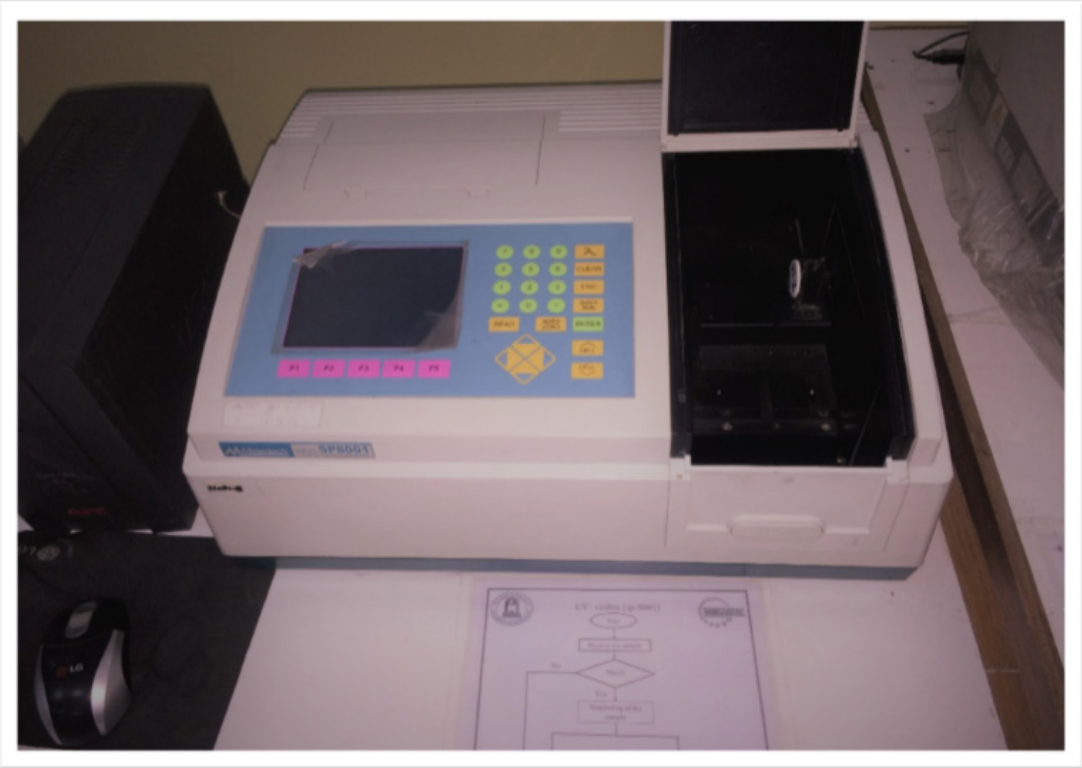

\section{Statistical Analysis}

Figure 3. Testing the specimens by UV devise (translucency )

The SPSS v 16 was used to analyze samples data, and provide a summary of mean and standard for comparison among groups.

\section{RESULTS}

All values of mean and standard deviation are deviation. The Tukey test and ANOVA test were used shown in the table 1.

Table 1. mean and standard deviation of all groups for translucency

\begin{tabular}{|c|c|c|}
\hline Groups & Mean & Standard deviation \\
\hline Control & 75.06 & 14.45 \\
\hline White 1 & 37.99 & 10.12 \\
\hline White 2 & 14.60 & 5.89 \\
\hline
\end{tabular}

As shown in the table 1, there was a significant there were highly significant differences among all decrease in values of mean of translucency with groups where $\mathrm{P}<0.001$ as illustrated in tukey HSD significant reduction in standard deviation for all multiple comparison test (Table 2). groups. In addition, one-way ANOVA revealed that

Table (2): Tukey HSD multiple comparison test (ANOVA)

\begin{tabular}{|c|c|c|c|c|}
\hline Groups & N & \multicolumn{3}{|c|}{ Subset for alpha $=0.05$} \\
\hline Control & 10 & 75.06 & & 3 \\
\hline White 1 & 10 & & 37.99 & \\
\hline White 2 & 10 & & & 14.60 \\
\hline Sig. & & 1.000 & 1.000 & 1.000 \\
\hline
\end{tabular}

\section{DISCUSSION}

In dentistry, acrylic resins are widely used due to their suitable biological, physical and mechanical properties. Such materials are also used for fabrication of scleral part of ocular prosthesis when mixed with oil paints to match the colour of normal eye. The aim of this study was to assess the translucency of acrylic resin following addition of titanium dioxide in two concentrations ( $1 \mathrm{ml}$ and $2 \mathrm{ml}$ ). Translucency is a property of substances that permits the passage of light but disperses the light, so objects cannot be seen through the material ${ }^{(11)}$. Translucency of material depends on their thickness and the scattering and absorption coefficients of the resin, filler particles, organic matrix, pigments, and opacifiers ${ }^{(12-14) .}$ The type, size, and number of internal filler particles affect light scattering in resin materials thus affecting the translucency. Lee $(2008)^{(14)}$ suggested there was an inverse correlation between translucency and filler content thus as the amount of filler increased translucency decreased. Translucency of esthetic materials is usually determined with the translucency parameter or contrast ratio. Translucency parameter refers to the colour difference between a uniform 
thickness of material over a black and white background, and corresponds directly to common visual assessments of translucency ${ }^{(15-16)}$. In this study, it was found that there was a significant decrease in values of mean of translucency with significant reduction in standard deviation. The study which was carried out by Aszrin et al., (2016) ${ }^{(17)}$ found that the use of different concentrations of $\mathrm{ZrO}_{2}-\mathrm{Al}_{2} \mathrm{O}_{3}-\mathrm{SiO}_{2}$ filler exhibits an erratic influence of translucency.

\section{CONCLUSION}

With the limitations of the study, the results showed a significant decrease in the translucency of clear acrylic resin following addition of the oil paint. The adding of white oil paint at $1 \mathrm{ml}$ to clear acrylic resin is gradually suitable in the manufacture of the scleral part of ocular prostheses to match the colour of natural eye.

\section{REFERENCES}

1. Noort R V. Introduction to dental materials. 3rd edition. Elsevier Limited,2007.

2. Jasim BS, Ismail IJ. The effect of silanized alumina nanofillers addition on some physical and mechanical properties of heat cured polymethyl methacrylate denture base material. Journal of Baghdad College of Dentistry.2014; 26(2):18-32.

3. Kati F, Al-Kaabi A.Part II: Effect of oil paint addition on the flexural strength of acrylic ocular prosthesis. 3rd international conference of medical and health speciality. 2016; 4(4):100-104.

4. Kati F, Al-Kaabi A. Part I: Effect of oil paint addition on micro hardness of acrylic ocular prosthesis. Iraqi Dental Journal. 2016; 38(2):87-89.

5. Jain DC, Hegde V,Aparna IN, DhanasekarB. Ocular prosthesis an esthetic vision.JNepalDenAsso.2010;11(1):101-106.

6. .Dheeraj K, Ajay G, Hemant G, Gaurav V. Ocular prosthesisa case report. Baba Farid University Dental Journal. 2010; 1(1): 52-54.
7. Artopoulou I, Montgomery P, Wesley P, Lemon J. Digital imaging in the fabrication of ocular prostheses. The Journal of Prosthetic Dentistry. 2006;95:327-30

8. Goiato MC, Nicolau EI, Mazaro JV. Mobility, aesthetic, implants, and satisfaction of the ocular prostheses wearers. Craniofacial Surgery Journal. 2010;21(1):160-164.

9. .Fernandes AU, Goiato MC, Santos DM. Effect of weathering and thickness on the superficial micro-hardness of acrylic resin and ocular button. The Journal of Contact Lens \& Anterior Eye. 2009;32(6):283-287.

10. ADA. American national standers institute/ American dental association specification No.12 for denture base polymer . 10th Ed. ; Chicago :council on dental material and devices.1999.

11. Powers JM, Sakaguchi RL. . Restorative dental materials. . 12th edition ed. St. Louis: Mosby; 2006.

12. Azzopardi N, Moharamzadeh K, Wood DJ, Martin N, van Noort R. Effect of resin matrix composition on the translucency of experimental dental composite resins. Dent Mater 2009;25(12):1564-8.

13. Lee YK. Influence of scattering/absorption characteristics on the color of resin composites. Dent Mater 2007;23(1):12431.

14. Perez MM, Ghinea R, Ugarte-Alvan LI, Pulgar R, Paravina RD. Colour and translucency in silorane-based resin composite compared to universal and nanofilled composites. J Dent 2010.

15. Johnston WM, Ma T, Kienle BH. Translucency parameter of colorants for maxillofacial prostheses. Int J Prosthodont 1995;8(1):79-86.

16. Johnston WM, Reisbick MH. Color and translucency changes during and after curing of esthetic restorative materials. Dent Mater 1997;13(2):89-97.

17. Aszrin F, Takarini V , Hasratiningsih Z, Bambang Purwasasmita B Translucency Evaluation of Polymethyl Methacrylate (PMMA) Reinforced with $\mathrm{ZrO}_{2}$ $\mathrm{Al}_{2} \mathrm{O}_{3}-\mathrm{SiO}_{2}$ Filler System in Fabricating Indirect Restoration. UIP HEALTH MED., 2016, 1(1) 